\title{
СОВЕРШЕНСТВОВАНИЕ СИСТЕМЫ ПОДДЕРЖКИ ЭКСПОРТА В РОССИИ С УЧЕТОМ ЗАРУБЕЖНОГО ОПЫТА *
}

\section{(c) 2019 Пищик Виктор Яковлевич}

доктор экономических наук, профессор департамента мировой экономики и мировых финансов Финансовый университет при Правительстве Российской Федерации, Россия, Москва

E-mail: pv915@mail.ru

\section{(C) 2019 Алексеев Петр Викторович}

кандидат экономических наук, ведущий научный сотрудник института исследований международных экономических отношений

Финансовый университет при Правительстве Российской Федерации, Россия, Москва

E-mail: apv31@mail.ru

Необходимость совершенствования системы поддержки экспорта в России обусловлена важной ролью экспорта в экономике нашей страны, необходимостью его увеличения и диверсификации структуры. В отличие от ведущих стран-экспортеров, система государственной поддержки экспорта в Российской Федерации не столь эффективна и находится в стадии становления и развития. На сегодня в России на правительственном уровне отсутствует единый координирующий орган, ответственный за согласование политики по поддержке экспорта, хотя за отдельными органами власти закреплены определенные функции и полномочия в данной сфере. В статье предлагается создать Консультативный совет по поддержке экспорта с закреплением за ним полномочий по развитию экспортной деятельности на федеральном правительственном уровне. Это позволит, по нашему мнению, повысить степень координации деятельности и ответственность действующих институтов поддержки экспорта.

Ключевые слова: система поддержки экспорта, внешнеэкономическая деятельность, мировой опыт, экспортная политика, внешнеэкономическая политика

Особенностью крупнейших стран-экспортеров (США, Германии, Великобритании, Японии, Китая) является наличие мощной и разветвленной системы государственных и негосударственных институтов, обеспечивающих системную поддержку экспорта товаров и услуг. Рассмотрим структуру данной системы в крупнейших странах-экспортерах.

Институциональная структура поддержки экспорта в США. В настоящее время в США действует многоуровневая система поддержки экспорта, включающая организации исполнительного уровня, организации руководящего уровня, а также консультативный орган (рисунок 1).

Рассмотрим уровни данной системы по отдельности.

1. Организации исполнительного уровня включают: Администрацию Президента (Бюро торгового представителя, Бюро управления и бюджета, Совет национальной безопасности и др.), Министерство торговли, Министерство сельского хозяйства и автономные государственные организации.

2. Значимую роль на руководящем уровне (при формировании экспортной политики и координации деятельности указанных выше и других министерств и ведомств) играют Координационный комитет по содействию торговли США (ККСТ) и Кабинет по поддержке экспорта (КПЭ). ККСТ действует под эгидой министерства торговли США и осуществляет координацию деятельности в общей сложности 20 министерств и ведомств, руководители которых являются его членами.

Основная функция Кабинета по поддержке экспорта состоит в усилении координации деятельности министерств и ведомств в сфере содействия ВЭД для обеспечения реализации Национальной экспортной инициативы (НЭИ), принятой в 2010 г. КПЭ возглавляет заместитель Секретаря по национальной безопасности США,

\footnotetext{
* Статья подготовлена по результатам исследований, выполненных за счет бюджетных средств по государственному заданию Финуниверситета.
} 

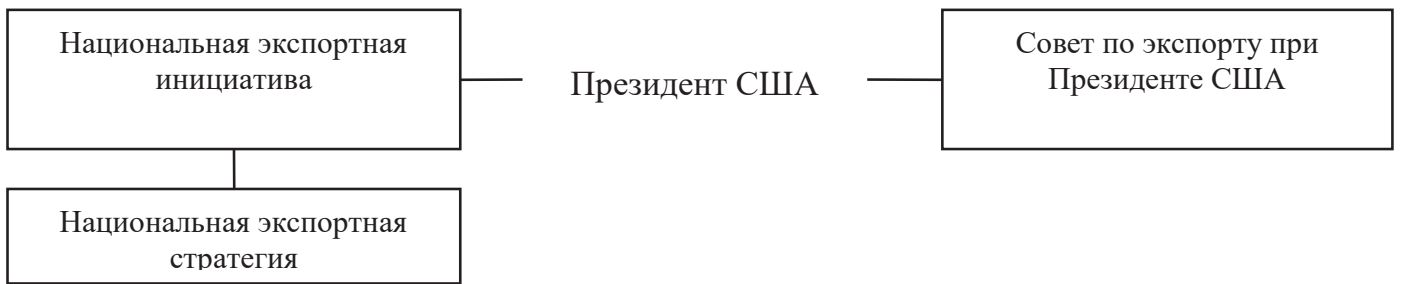
стратегия

Государственные институты

руководящего уровня

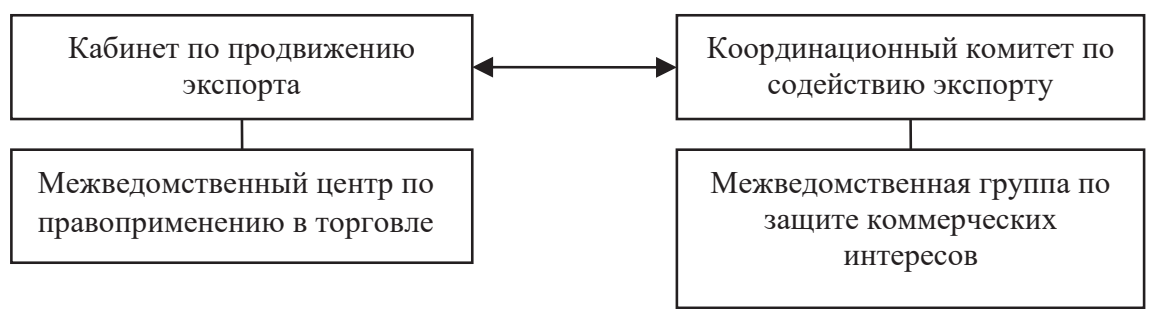

Государственные институты поддержки экспорта на исполнительном уровне

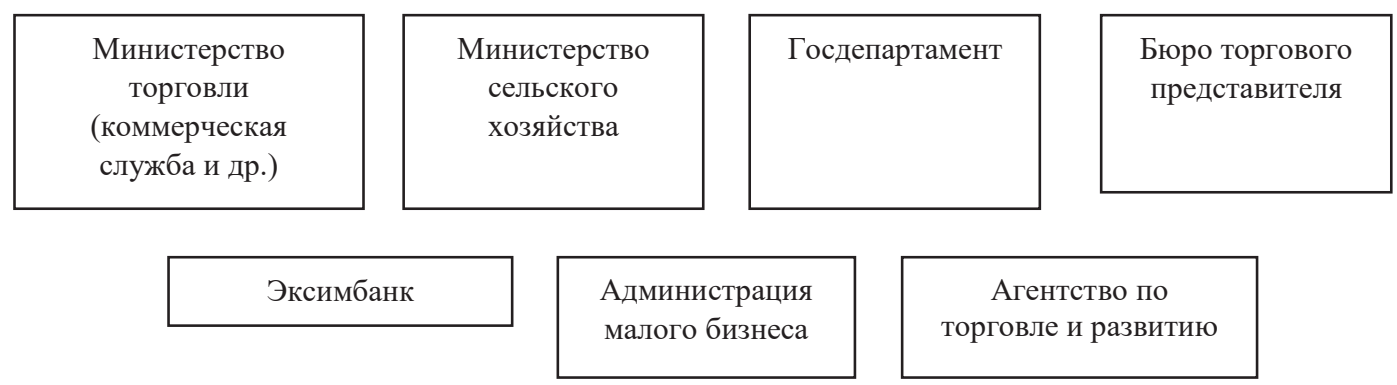

Рисунок 1. Основные государственные институты в сфере поддержки экспорта в США [1]

а его членами являются Государственный секретарь, министры финансов и торговли, ключевые советники администрации и главы ведущих государственных экономических и торговых агентств.

3. Консультативным органом в сфере международной торговли является Совет по экспорту при Президенте США, созданный в 1973 г., который осуществляет подготовку рекомендаций по развитию внешней торговли и расширению экспорта. В его состав входят представители предпринимательских кругов, законодательной и исполнительной власти, руководители профсоюзов и фермерских организаций.

Институциональная структура поддержки экспорта в Германии. Система поддержки экспорта в Германии охватывает свыше 300 различных организаций. Она контролируется Министерством иностранных дел, Министерством экономики и включает зарубежные внешнеторговые палаты (ВТП), а также ряд финансовых институтов и публичных организаций (рисунок 2).

Зарубежные ВТП Германии, контролируемые Объединением германских торгово-промышленных палат, расположены в наиболее важных для немецкой экономики странах (США, Индия, Китай, Бразилия, Россия, страны АСЕАН, Центральной Америки и др.) и выполняют широкий круг функций по развитию внешнеэкономических связей с ними и оказанию деловых услуг немецким экспортерам.

На начало 2019 г. в 92 странах действовали 140 зарубежных ВТП Германии [3].

Институциональная структура поддержки экспорта в Великобритании характеризуется высоким уровнем централизации, являясь сравнительно компактной. При этом полномо- 
Институты поддержки ВЭД на федеральном уровне

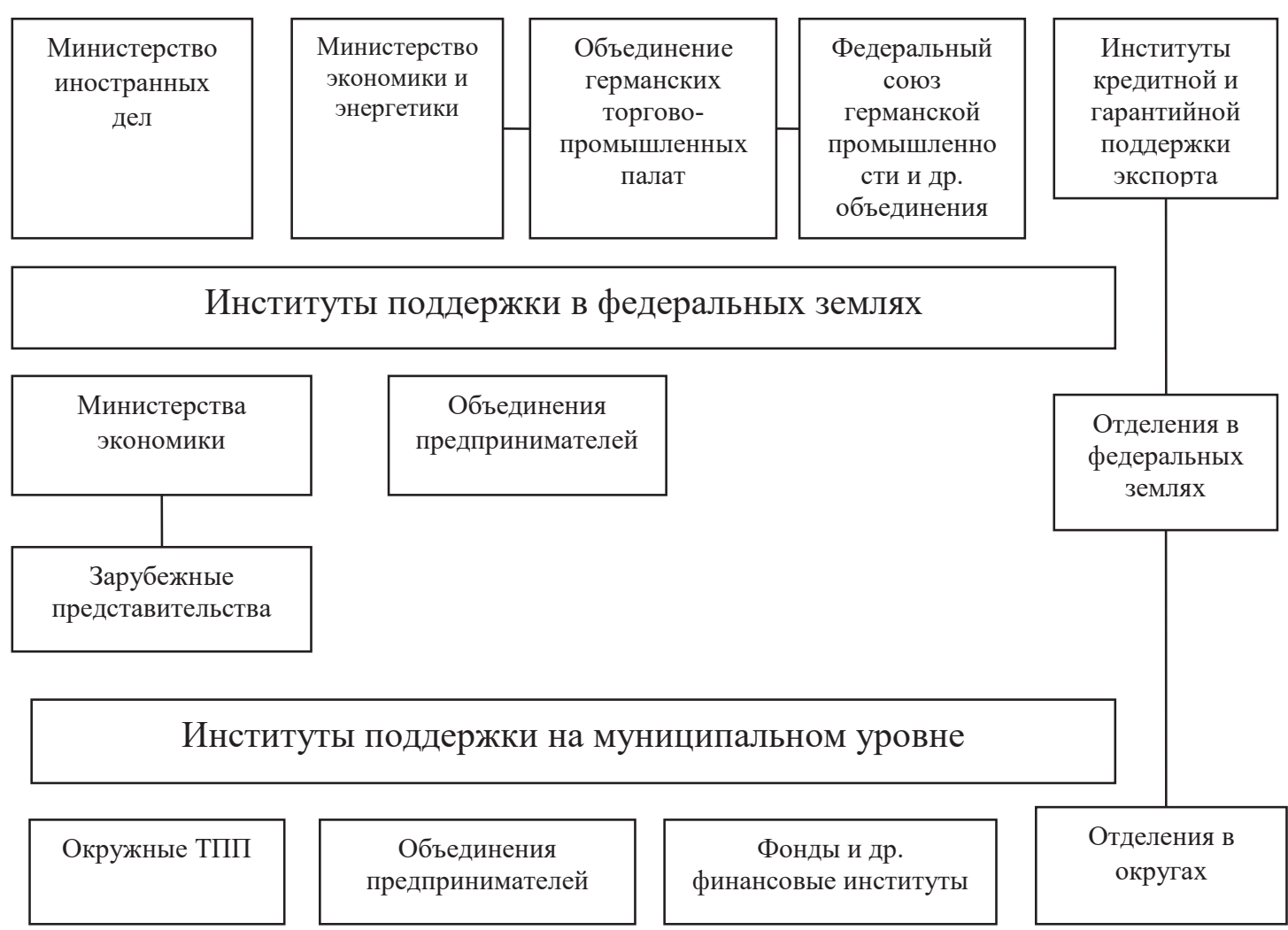

Рисунок 2. Основные институты национальной системы поддержки экспорта Германии [1]

чия и ответственность разделены между двумя ключевыми министерствами: Министерством иностранных дел и Министерством предпринимательства, инноваций и профессионального образования (рисунок 3).

Стержневой фигурой системы поддержки экспорта является Государственный министр торговли и инвестиций, который возглавляет Департамент межведомственной координации вопросов международной торговли и привлечения иностранных инвестиций МИДа, а в Министерстве предпринимательства, инноваций и профессионального образования - Департамент торговли и инвестиций. Помимо этого, важными функциями Государственного министра являются:

- контроль над деятельностью Государственного агентства по развитию ВЭД (UK Trade \& Invest, UKTI);

- организация взаимодействия правитель- ства с государственным агентством по оказанию кредитной и гарантийно-страховой поддержки экспортерам - UK Export Finance (UKEF)*;

- функция спикера лондонского правительства в Палате лордов по делам торговли и инвестиций.

Система поддержки экспорта в Японии характеризуется высоким уровнем централизации и контроля со стороны органов государственного управления. Руководящим ведомством и координатором в данной сфере выступает Министерство экономики, торговли и промышленности Японии (МЭТП). Ключевым институтом исполнительного звена является действующая с 1958 г. Организация содействия развитию внешней торговли Японии (JETRO), основной функцией которой является оказание информационно-аналитических, консультационных, промоутерских услуг национальному экспортно-ориентированному бизнесу. Финансирова-

* В 2017 г. общий объем финансовой поддержки UKEF составил 0,2 млрд. долл., не изменившись по сравнению с 2016 г. [2]. 
Государственное агентство по развитию ВЭД - UK Trade \& Invest

- Координирует деятельность всех других государственных институтов в сфере поддержки экспорта на национальном и региональном уровнях;

- Взаимодействует с институтами развития Уэльса, Шотландии и Северной Ирландии;

- Является главной сервисной организацией в сфере поддержки экспорта и привлечения ПИИ.

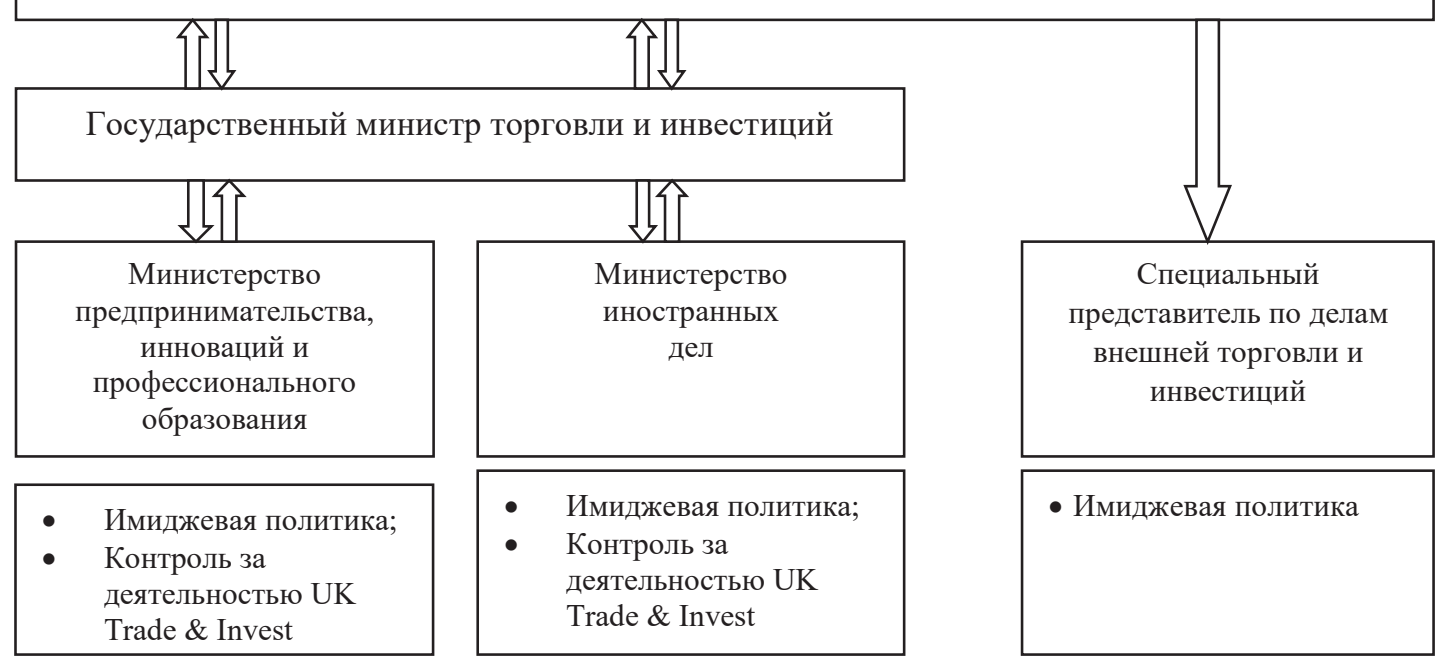

Рисунок 3. Основные государственные институты системы поддержки экспорта Великобритании [1]

нием экспорта, включая кредитование и страхование, занимается государственный Японский банк международного сотрудничества, а основным институтом по страхованию экспортных кредитов является Японская корпорация по страхованию экспорта и инвестиций (NEXI). В 2016 г. и в 2017 г. объем страховой поддержки NEXI составил соответственно 52,9 млрд. долл. и 51,4 млрд. долл. [2].

В системе поддержки экспорта Китая главным руководящим звеном является Министерство коммерции КНР, отвечающее за разработку и реализацию внешнеэкономической политики страны. Под руководством Минкоммерции, в 140 странах функционируют около 180 торговых представительств КНР, выполняющих задачи по продвижению китайского экспорта на внешние рынки.

Важное значение в системе поддержки экспорта имеет Китайский Совет по содействию международной торговле (известный также под другим официальным названием - Китайская международная торговая палата), занимающийся стимулированием внешнеэкономической деятельности, привлечением передовых технологий, развитием международного экономического и технического сотрудничества.

Финансированием, кредитованием и страхованием экспорта занимаются три государственных института - Эксимбанк Китая*, экспортное страховое агентство Sinosure** и Банк развития Китая****; контролируемые Министерством коммерции, Министерством финансов, МИД Китая.

\footnotetext{
* Основными задачами Эксимбанка Китая являются реализация национальной внешнеэкономической политики и содействие продвижению китайских товаров на внешние рынки. Банк предлагает следующие финансовые продукты: кредитование внешнеторговых операций (китайских экспортеров и иностранных покупателей), зарубежных строительных и инвестиционных проектов, госпрограммы льготного финансирования, банковские гарантии и др. [1].

**: Китайское экспортное агентство Sinosure, созданное в 2001 г. с целью развития китайского экспорта, предоставляет полный спектр страховых услуг национальным экспортерам. В 2017 г. объем страховой поддержки Sinosure составил 412,8 млрд. долл. (375,2 млрд. долл. в 2016 г.) [2].

**** Основной функцией Банка развития Китая в сфере поддержки экспорта является проведение операций по кредитованию местных экспортеров. В последние годы большое внимание банк уделяет кредитованию проектов в сфере так называемой «зеленой энергетики», благодаря чему китайские компании добились серьезных успехов в борьбе с западными концернами [1].
} 


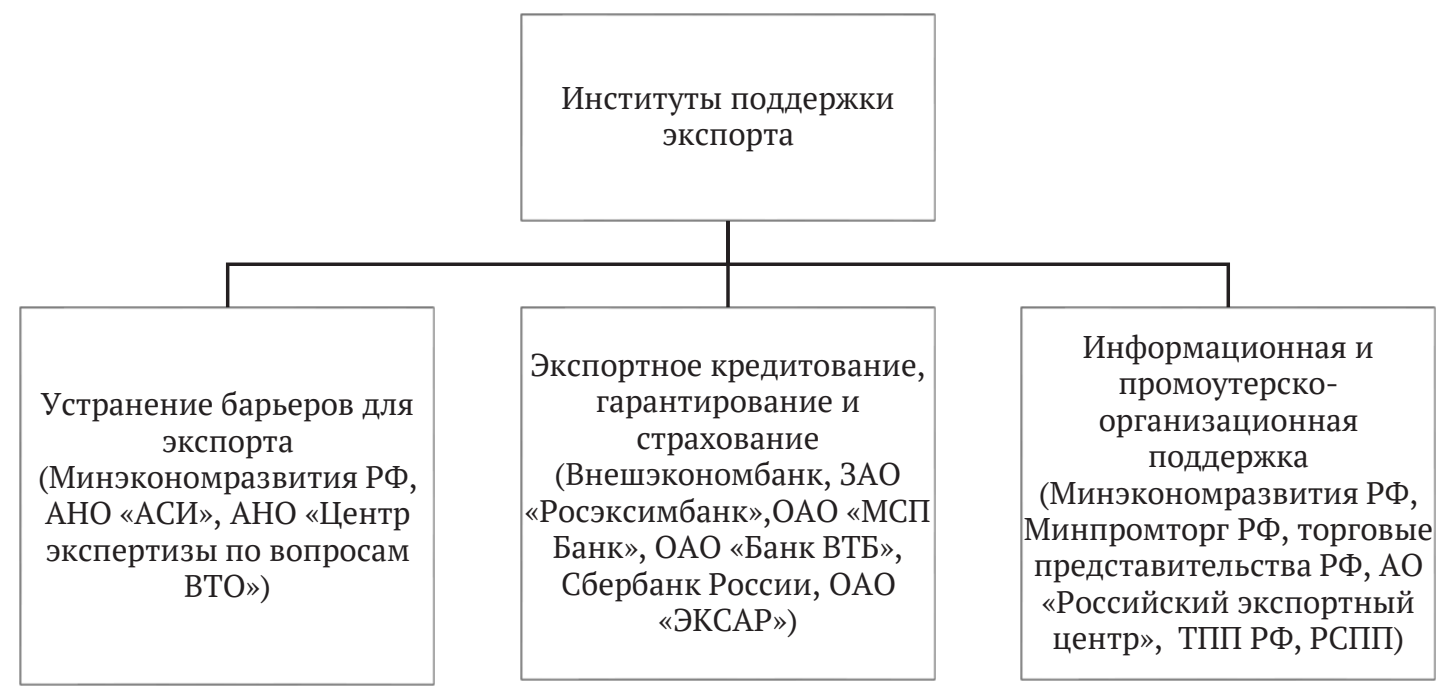

Рисунок 4. Основные институты поддержки экспорта в Российской Федерации и их функции Источник: составлено авторами

Система институтов поддержки экспорma в России. В отличие от ведущих стран-экспортеров, система государственной поддержки экспорта в Российской Федерации не столь развита, поскольку формируется на протяжении незначительного периода времени, в основном, в течение последних 25 лет. В настоящее время в Российской Федерации действуют институты поддержки экспорта товаров и услуг, составляющие разветвленную систему (рисунок 4).

Для развития и совершенствования системы поддержки экспорта в России целесообразно использовать позитивный опыт передовых стран-экспортеров. Так, например, особенностью США является наличие центра ответственности за проводимую политику в сфере поддержки экспорта в виде Совета по экспорту при Президенте США, что обеспечивает высокий уровень координации деятельности различных государственных институтов.

В России на государственном уровне до сих пор не создан единый центр ответственности за координацию политики в сфере поддержки экспорта. Определенные функции, задачи и полномочия в этой сфере закреплены за отдельными органами исполнительной власти. В связи с этим, на наш взгляд, целесообразно учредить
Консультативный совет по поддержке экспорта (по аналогии с Консультативным советом по иностранным инвестициям) и сосредоточить в этом органе полномочия по развитию экспортной деятельности и координации деятельности институтов поддержки экспорта [4].

К числу важнейших задач Консультативного совета по поддержке экспорта могли бы быть отнесены:

- повышение стандартов администрирования в сфере формирования и реализации экспортного потенциала страны на основе преимущественного развития несырьевого экспорта;

- создание условий для плавного перехода предпринимательского корпуса Российской Федерации в русло диверсифицированного промышленного бизнеса с учетом потребностей партнеров;

- создание условий для увеличения объемов инвестиций в высокотехнологичный экспортный сектор [4].

Создание и работа Консультативного совета по поддержке экспорта могли бы повысить степень координации деятельности институтов развития и стимулирования экспорта, что окажет содействие существенному увеличению объемов российского несырьевого экспорта.

\section{Библиографический список}

1 Спартак А.Н., Французов В.В., Хохлов А.В. Мировой и российский экспорт: тенденции и перспективы развития, системы поддержки: монография.-М.: ВАВТ, 2015.

2 Competitiveness Report of the Eximbank of the US. URL: https://www.exim.gov/sites/default/files/reports/ competitiveness_reports/2017/CompetitivenessReport_FINALProof.pdf. Дата обращения: 21.05.2019.

3 AHK Deutsche Auslandshandelskammern. URL://www.ahk.de. Дата обращения: 18.05.2019.

4 Ищенко Е.Г., Алексеев П.В. Совершенствование механизма поддержки экспорта в России // Деньги и кредит. 2015. № 9. C. 36-42. 